\title{
Elastase induced lung epithelial cell apoptosis and emphysema through placenta growth factor
}

\author{
H-H Hou ${ }^{1,2,5}$, S-L Cheng ${ }^{3,4,5}$, H-T Liu ${ }^{1,2}$, F-Z Yang ${ }^{3}$, H-C Wang ${ }^{*, 1,2,6}$ and C-J Yu*,1,2,6
}

Chronic pulmonary obstructive disease (COPD) is the fourth leading cause of death worldwide, however, the pathogenic factors and mechanisms are not fully understood. Pulmonary emphysema is one of the major components of COPD and is thought to result from oxidative stress, chronic inflammation, protease-antiprotease imbalance and lung epithelial (LE) cell apoptosis. In our previous studies, COPD patients were noted to have higher levels of placenta growth factor (PIGF) in serum and bronchoalveolar lavage fluid than controls. In addition, transgenic mice overexpressing PIGF developed pulmonary emphysema and exposure to PIGF in LE cells induced apoptosis. Furthermore, intratracheal instillation of porcine pancreatic elastase (PPE) on to PIGF wild type mice induced emphysema, but not in PIGF knockout mice. Therefore, we hypothesized that PPE generates pulmonary emphysema through the upregulation of PIGF expression in LE cells. The elevation of PIGF then leads to LE cell apoptosis. In the present study, we investigated whether PPE induces PIGF expression, whether PIGF induces apoptosis and whether the downstream mechanisms of PIGF are related to LE cell apoptosis. We found that PPE increased PIGF secretion and expression both in vivo and in vitro. Moreover, PIGF-induced LE cell apoptosis and PPE-induced emphysema in the mice were mediated by c-Jun N-terminal kinase (JNK) and p38 mitogen-activated protein kinase (p38 MAPK) pathways. Given these findings, we suggest that the increase in PIGF and PIGF-induced JNK and p38 MAPK pathways contribute to PPE-induced LE cell apoptosis and emphysema. Regulatory control of PIGF and agents against its downstream signals may be potential therapeutic targets for COPD.

Cell Death and Disease (2013) 4, e793; doi:10.1038/cddis.2013.329; published online 5 September 2013

Subject Category: Experimental Medicine

Chronic pulmonary obstructive disease (COPD) is the fourth leading cause of death worldwide with high mortality and morbidity rates even under advanced medical care. ${ }^{1}$ Emphysema is a major component of COPD and is characterized by destruction and enlargement of the alveolar region through chronic inflammation, oxidative stress and protease-antiprotease imbalance. ${ }^{2,3}$ However, the factors and pathogenic mechanisms that cause COPD are not fully understood. ${ }^{4}$ Apoptosis of lung epithelial (LE) cells is one of the potential factors involved in the pathogenesis of COPD. ${ }^{5}$ Tsao et al. ${ }^{6}$ demonstrated that exogenous placenta growth factor (PIGF) induced LE cell apoptosis and inhibited cellular proliferation, and that the transgenic mice with over-expressed PIGF developed emphysema phenotype, suggesting that PIGF has an important role in the pathogenesis of emphysema.

PIGF belongs to a family of vascular endothelial growth factors (VEGF) and the major biological function of PIGF is promoting angiogenesis through VEGF receptor-1 (VEGFR1) signaling. ${ }^{7,8}$ PIGF expresses in the placenta, heart, lung, thyroid, brain and skeletal muscles. ${ }^{9}$ Increasing evidence suggest that PIGF expressed in LE cells may contribute to the progression of COPD. Cheng et al. ${ }^{10}$ reported that patients with COPD had higher levels of PIGF in serum and bronchoalveolar lavage (BAL) fluid, and that the level of PIGF was inversely related to lung function. Moreover, cigarette smoke, a major factor related to COPD, has been found to increase PIGF expression in rat lungs. ${ }^{11}$ Furthermore, ablation of PIGF has been found to protect mice from porcine pancreatic elastase (PPE)-induced emphysema. ${ }^{12}$ However, the detailed mechanisms underlining PIGF-induced LE cell apoptosis and the pathogenesis of emphysema remain to be elucidated.

PPE is a protease that can induce protease-antiprotease imbalance and has been applied in an animal model of emphysema and COPD. ${ }^{13}$ Previous studies have

\footnotetext{
${ }^{1}$ Department of Internal Medicine, National Taiwan University Hospital, Taipei, Taiwan; ${ }^{2}$ Department of Internal Medicine, National Taiwan University, College of Medicine, Taipei, Taiwan; ${ }^{3}$ Department of Internal Medicine, Far Eastern Memorial Hospital, New Taipei City, Taiwan and ${ }^{4}$ Department of Chemical Engineering and Materials Science, Yuan-Ze University, Taoyuan, Taiwan

${ }^{*}$ Corresponding authors: H-C Wang or C-J Yu, Department of Internal Medicine, National Taiwan University Hospital, No. 7, Chung-Shan South Road, Taipei, Taiwan. Tel: + + 8862 29251024; Fax: + 8862 23582867; E-mail: haochienwang@ gmail.com or jefferycjyu@ @ntu.edu.tw

${ }^{5}$ These authors contributed equally to this work.

${ }^{6}$ These authors contributed equally to this work.

Keywords: placenta growth factor; chronic pulmonary obstructive disease; emphysema; apoptosis

Abbrevations: COPD, chronic pulmonary obstructive disease; LE, lung epithelial; PIGF, placenta growth factor; PPE, porcine pancreatic elastase; JNK, c-Jun N-terminal kinase; MAPK, mitogen-activated protein kinase; VEGF, vascular endothelial growth factor; VEGFR1, VEGF receptor-1; BAL, bronchoalveolar lavage; NE, neutrophil elastase; IL-8, interleukin-8; MMP-2, matrix matelloprotease-2; Egr-1, early growth response-1; ELISA, enzyme-linked immunosorbent assay; ChIP, chromatin immunoprecipitation; GAPDH, glyceraldehyde 3-phosphate dehydrogenase; TUNEL, terminal deoxynucleotidyl transferase dUTP nick end labeling; IHC, immunohistochemistry

Received 07.5.13; revised 25.7.13; accepted 29.7.13; Edited by M Agostini
} 
demonstrated that leukocyte elastase increases lung and intestinal epithelial cells apoptosis. ${ }^{14,15}$ Neutrophil elastase (NE) has been shown to increase the expression and secretion of elafin in type II alveolar epithelial cells. ${ }^{16}$ Moreover, NE has also been shown to increase the expression of MUC4 and MUC5AC ${ }^{17,18}$ and promote the secretion of mucin and expression of interleukin-8 (IL-8) in human bronchial epithelial cells. ${ }^{19,20}$ Other than LE cells, NE has also been shown to upregulate cathepsin $B$ and matrix matelloprotease-2 (MMP-2) in macrophages. ${ }^{21}$ To date, the mechanisms by which elastase induces LE cell apoptosis have not been established. In this study, we hypothesized that PPE generates LE cell apoptosis and pulmonary emphysema through the expression of PIGF and PIGF-mediated downstream signaling.

We found that PPE increased PIGF mRNA and protein expressions in vivo and in vitro. PPE stimulates PIGF promoter activity by early growth response-1 (Egr-1) and Egr-1 response element. Moreover, PIGF induced LE cell apoptosis in a dosedependent manner, and chronic treatment of PIGF increased LE cell apoptosis. Furthermore, PIGF activated c-Jun N-terminal kinase (JNK) and p38 mitogen-activated protein kinase (MAPK) pathways, both of which were involved in PIGF-induced LE cell apoptosis and PPE-induced pulmonary emphysema in mice. These novel findings may provide possible therapeutic strategies for emphysema and COPD.

\section{Results}

PPE treatment increased PIGF expression and secretion in LE cells. Previous study indicated $100 \mathrm{mU} / \mathrm{ml} \mathrm{NE}$ increases elafin gene expression in A549 cells ${ }^{16}$ and PIGF is majorly secreted by alveolar type II epithelial cells., ${ }^{6,22}$ Therefore, the mouse LE cells, mouse alveolar type II epithelial cells (MLE-15), were treated with 0-60 mU/ml PPE for $24 \mathrm{~h}$ to test whether PPE could induce PIGF expression. The secretion of PIGF into the medium was promoted by $60 \mathrm{mU} / \mathrm{ml}$ PPE treatment (Figure 1a). In MLE-15 cells, the mouse PIGF promoter region $(2.5 \mathrm{~kb})$-driven luciferase activity indicated that $60 \mathrm{mU} / \mathrm{ml}$ PPE increased the mouse PIGF promoter activity by about threefold (Figure $1 \mathrm{~b}$ ). The results of reverse transcriptional (RT)-PCR and western blot demonstrated that $60 \mathrm{mU} / \mathrm{ml}$ PPE upregulated the expressions of PIGF mRNA and protein in the MLE-15 cells (Figures 1c and d). To study the transcriptional regulatory mechanism of PPE on PIGF expression, we analyzed the sequence of human PIGF promoter region and identified a speculated Egr-1 response element (CCCGCCCC) within 100 bp from transcriptional start site. ${ }^{23,24}$ Western blot demonstrated that $60 \mathrm{mU} / \mathrm{ml}$ PPE transiently increased the expressions of Egr-1 in MLE-15 cells (Figure 1e). The data of chromatin immunoprecipitation assay showed that the exposure to $60 \mathrm{mU} / \mathrm{ml}$ PPE for $1 \mathrm{~h}$ would promote the association of Egr-1 protein and PIGF promoter region (Figure 1f). These findings confirmed that PPE increased PIGF expression and secretion in mouse LE cells.

Exogenous PIGF induced LE cell apoptosis. Previous study indicated that $100 \mathrm{ng} / \mathrm{ml}$ PIGF induced MLE-15 cell apoptosis. ${ }^{6}$ In this study, MLE-15 cells were treated with 0-100 ng/ml mouse recombinant PIGF for $24 \mathrm{~h}$. Exogenous
PIGF dose-dependently increased the level of apoptosis in the MLE-15 cells according to the results of the caspase- 3 activity assay (Figure 2a), trypan blue inclusion analysis (Figure 2b), flow cytometric assay (Figure 2c) and terminal deoxynucleotidyl transferase dUTP nick end labeling (TUNEL) assay (Figure 2d). Because the level of cells with trypan blue stain is similar to FITC-positive cell and a few annexin V-positive cells in cytomertic assay, PIGF majorly induced apoptotic cellular death rather than necrotic cellular death in LE cells. In addition, S cells were treated with $0-100 \mathrm{ng} / \mathrm{ml}$ human recombinant PIGF for $24 \mathrm{~h}$. The results of the caspase- 3 activity assay demonstrated that PIGF also increased human LE cell apoptosis in a dosedependent manner (Figure 2e). Our previous study indicated co-treatment of $50 \mathrm{pg} / \mathrm{ml}$ PIGF, $200 \mathrm{pg} / \mathrm{ml}$ interleukin-8 (IL-8) and $200 \mathrm{pg} / \mathrm{ml}$ tumor necrosis factor- $\alpha(\mathrm{TNF} \alpha)$ for 14 days induced S-cell apoptosis. ${ }^{10}$ To mimic the chronic damage conditions in COPD, the S cells were treated with $800 \mathrm{pg} / \mathrm{ml}$ human recombinant PIGF for 14 days. The dose of PPE was dependent on PPE-induced PIGF secretion in $S$ cells (data not shown). Chronic treatment with $800 \mathrm{pg} / \mathrm{ml}$ PIGF resulted in a similar apoptotic level as Figure 2e (Figure 2f). Taken together, these results confirmed that both $24 \mathrm{~h}$ and 14 days of treatment of PIGF increased LE cell apoptosis.

Exogenous PIGF activated JNK and p38 MAPK pathways in LE cells. To elucidate the detailed mechanism involved in PIGF-induced LE cell apoptosis, we treated MLE-15 cells with $100 \mathrm{ng} / \mathrm{ml} \mathrm{PIGF}$ for $0-24 \mathrm{~h}$. According to the results of western blot, PIGF induced prolonged and enhanced phosphorylation of JNK and p38 MAPK after $6 \mathrm{~h}$ of treatment (Figures $3 a$ and b). But PIGF had no significant effect on other signaling pathways like Akt and $\mathrm{NF}_{\kappa} \mathrm{B}$ (Supplementary Figure 1S). The 14-day treatment of $S$ cells with $800 \mathrm{pg} / \mathrm{ml}$ of PIGF also increased the activation of JNK and p38 MAPK (Figures $3 c$ and $d$ ). These results suggest that the JNK and p38 MAPK pathways may have crucial roles in PIGF-induced mouse and human LE cell apoptosis.

Inhibition of the JNK and p38 MAPK pathways abrogated PIGF-induced LE cell apoptosis. To evaluate the roles of JNK and p38 MAPK in PIGF-induced LE cell apoptosis, MLE-15 and S cells were pretreated with inhibitors of JNK and p38 MAPK, SP 600125 and SB 203580, respectively, to block the JNK and p38 MAPK pathways. According to the results of the caspase-3 activity assay (Figure 4a), trypan blue inclusion analysis (Figure 4b), flow cytometric assay (Figure 4c) and TUNEL assay (Figure 4d), blockage of the JNK and p38 MAPK pathways caused attenuation of apoptosis in the PIGF-treated MLE-15 cells (100 ng/ml for $24 \mathrm{~h}$ ). In addition, inhibition of the JNK and p38 MAPK signaling decreased the level of apoptosis in PIGF-treated MLE-15 $(100 \mathrm{ng} / \mathrm{ml}$ for $24 \mathrm{~h}$ ) and $\mathrm{S}$ cells ( $800 \mathrm{pg} / \mathrm{ml}$ for 14 days) as shown in caspase3 activity assay (Figures $4 \mathrm{e}$ and f). These results strongly confirmed that JNK and p38 MAPK signaling are involved in PIGF-stimulated mouse and human LE cell apoptosis.

Intratracheal PPE instillation increased PIGF expression and secretion and downstream JNK and p38 MAPK pathway activation. The role of PIGF in PPE-induced LE 

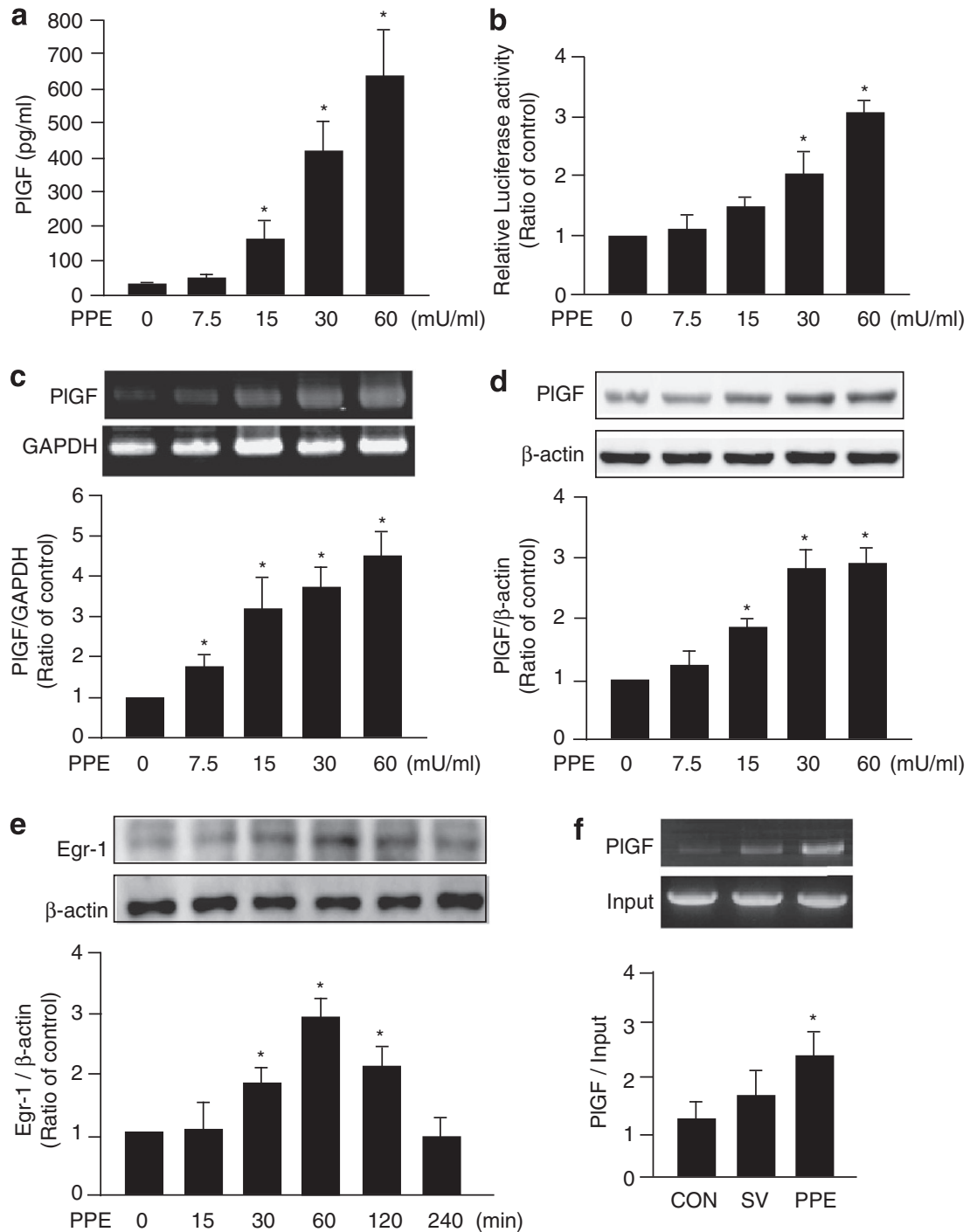

Figure 1 Treatment of porcine pancreatic elastase (PPE) increased the expression and secretion of placenta growth factor (PIGF) in lung epithelial (LE) cells. Mouse alveolar type II epithelial cells, MLE-15, were washed twice with PBS then incubated in the medium without serum and treated with 0-60 mU/ml PPE for $24 \mathrm{~h}$ (a-d), $4 \mathrm{~h}$ (e) or $1 \mathrm{~h}(\mathrm{f})$. The level of PIGF in the culture medium was detected by ELISA (a). The activity of PIGF promoter in the cellular lysate was evaluated by luciferase activity (b). The mRNA level of PIGF was determined by reverse transcriptional PCR with primer sets for PIGF and GAPDH cDNA (c). Cellular lysates were also subjected to western blot analysis with antibodies for PIGF (d) or Egr-1 (e) and $\beta$-actin. The association of Egr-1 and PIGF promoter was evaluated by chromatin immunoprecipitation assay (f). Data are presented as mean \pm S.E.M. ${ }^{*} P<0.05$ versus vehicle-treated group

cell apoptosis and emphysema was evaluated in an animal model. C57BL/6 mice were intratracheally instillated with saline (CON) or $100 \mathrm{mU} / \mathrm{ml}$ PPE (PPE) weekly for one month. The pulmonary cells of the PPE-treated mice displayed more expression of PIGF than the control mice, and the induced-PIGF majorly presented in LE cells (arrowheads in Figure 5a). The induction of PPE on PIGF expression as well as activation of JNK and p38 MAPK were further confirmed by western blot analysis (Supplementary Figure 2S). Moreover, PPE-treated mice displayed more phosphorylated JNK and p38 MAPK levels than the control mice (arrowheads in Figure 5a). In addition, the BAL fluid of the PPE-treated mice had higher PIGF levels than that of the control mice (Figure 5b). These results demonstrated that PPE instillation increase PIGF expression, activation of JNK and p38 MAPK, and PIGF secretion in the pulmonary cells of mice.
PIGF and PIGF-activated JNK and p38 MAPK pathways were involved in PPE-induced apoptosis and emphysema in mice. To evaluate the roles of PIGF, JNK and p38 MAPK signaling in PPE-induced emphysema, $50 \mathrm{mg} / \mathrm{kg}$ of SP 600125 (JNK inhibitor), $50 \mathrm{mg} / \mathrm{kg}$ SB 603580 (p38 MAPK inhibitor), $3 \mathrm{mg} / \mathrm{kg}$ scramble siRNA and $3 \mathrm{mg} / \mathrm{kg}$ PIGF siRNA were co-treated with PPE instillation (PPE SP, PPE SB, PPE Sc-si and PPE PI-si) weekly for one month. Both RT-PCR and western blot analysis confirmed the attenuation of PIGF expressions by PIGF siRNA (Supplementary Figure 3S). TUNEL assay indicated apoptotic cells in pulmonary tissue (Figure 6a), and the PPE-treated mice had a higher level of pulmonary apoptosis than the control mice (Figure 6c). Moreover, the PPEtreated mice had the emphysema phenotype with enlargement of the alveolar space (Figure 6b) as evaluated by 
a

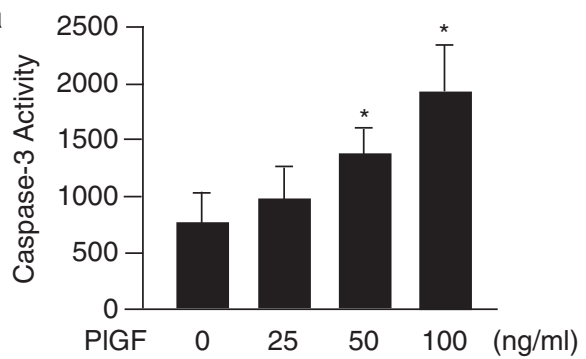

c

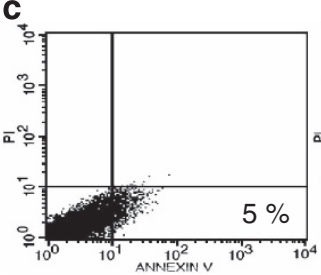

PIGF $0 \mathrm{ng} / \mathrm{ml}$

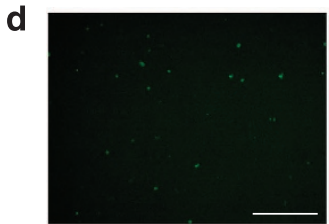

PIGF 0 ng/ml

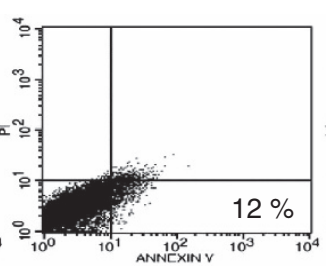

PIGF $25 \mathrm{ng} / \mathrm{ml}$

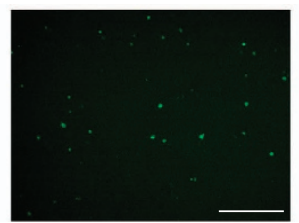

PIGF 25 ng/ml

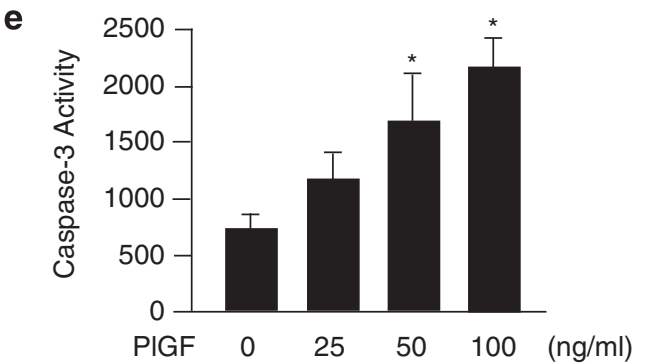

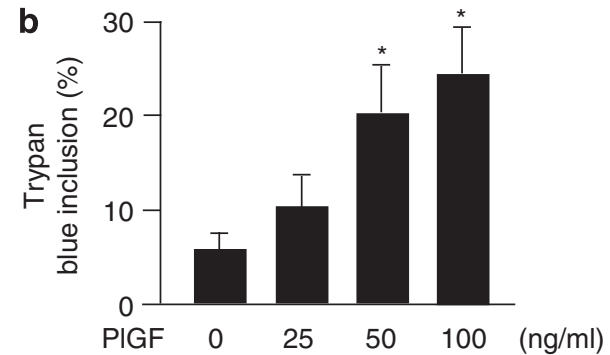

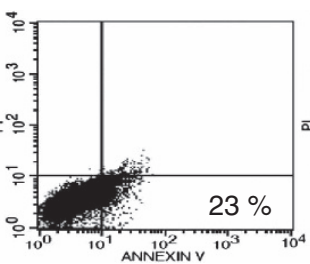

PIGF $50 \mathrm{ng} / \mathrm{ml}$

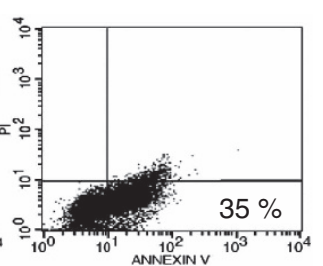

PIGF 100 ng/ml

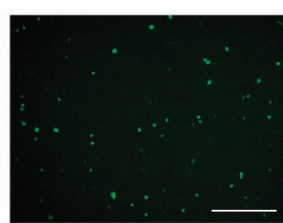

PIGF $50 \mathrm{ng} / \mathrm{ml}$

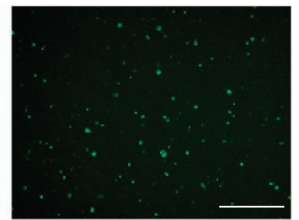

PIGF $100 \mathrm{ng} / \mathrm{ml}$

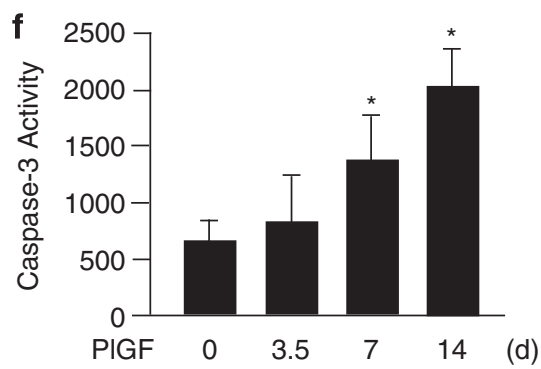

Figure 2 Exogenous PIGF induced LE cell apoptosis. MLE-15 cells were treated with $0-100 \mathrm{ng} / \mathrm{ml}$ recombinant mouse PIGF for $24 \mathrm{~h}$ (a-d). S cells were treated with $0-100 \mathrm{ng} / \mathrm{ml}(\mathbf{e})$ or $800 \mathrm{pg} / \mathrm{ml}$ (f) recombinant human PIGF for $24 \mathrm{~h} \mathrm{(e)} \mathrm{or} 14$ days (f). The PIGF-induced apoptosis was evaluated by relative signals in a caspase-3 activity assay that are presented as relative fluorescence units (RFU)/min per mg protein (a, e and f), blue-stained cells in trypan blue inclusion assay (b), annexin V-FITC-stained cells in flow cytometric assay (c) and fluorescent cells in terminal deoxynucleotidyl transferase dUTP nick end label (TUNEL) assay (d). Scale bar $=100 \mu \mathrm{m}$. Data are presented as mean \pm S.E.M. ${ }^{*} P<0.05$ versus vehicle-treated group

mean linear intercept (MLI) (Figure 6d). In addition, blockage of the JNK and p-38 MAPK pathways (PPE SP and PPE SB) and silencing of PIGF (PPE PI-si) attenuated the levels of PPE-induced pulmonary apoptosis (Figures 6a and c) and the air space enlargement in PPE-treated mice (Figures $6 b$ and d). Collectively, our in vivo experiments further confirmed that the PPE-increased pulmonary PIGF and the JNK and p38 MAPK signaling pathways were involved in PPE-induced pulmonary apoptosis and emphysema in vivo.

\section{Discussion}

Several studies have reported that elastase, a serine protease, induces epithelial cell apoptosis. Leukocyte elastase damages the intestinal epithelial cells via loss of mitochondrial integrity, and decreasing Akt and increasing JNK signaling. ${ }^{15}$ Moreover, the leukocyte elastase-induced LE cell apoptosis has been shown to be mediated by protease-activated receptor-1, and retinoic acid has been shown to abrogate leukocyte elastaseinduced LE cell apoptosis. ${ }^{14,25}$ Different from previously established mechanisms, our results showed for the first time that PPE resulted in LE cell apoptosis through PPE-induced PIGF expression and PIGF-mediated downstream JNK and p38 MAPK signaling pathways.

Our study demonstrated that treatment of $60 \mathrm{mU} / \mathrm{ml} \mathrm{PPE}$ for $24 \mathrm{~h}$ increased PIGF expression and secretion in LE cells. Tsao et al. ${ }^{6}$ had shown that treatment of $100 \mathrm{ng} / \mathrm{ml}$ PIGF for $24 \mathrm{~h}$ triggered MLE-15 cell apoptosis at the same level as our finding in this study. According to this condition, we indentified JNK and p38 MAPK signaling pathways are involved in PIGFinduced LE apoptosis. Moreover, treatment of PPE induced 


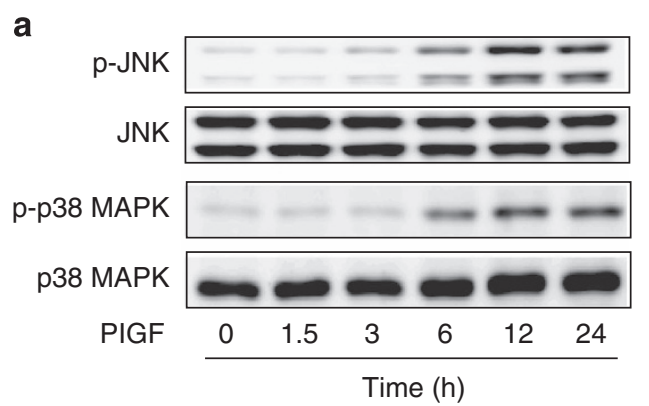

C
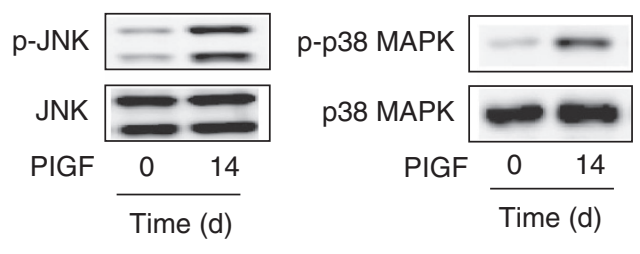
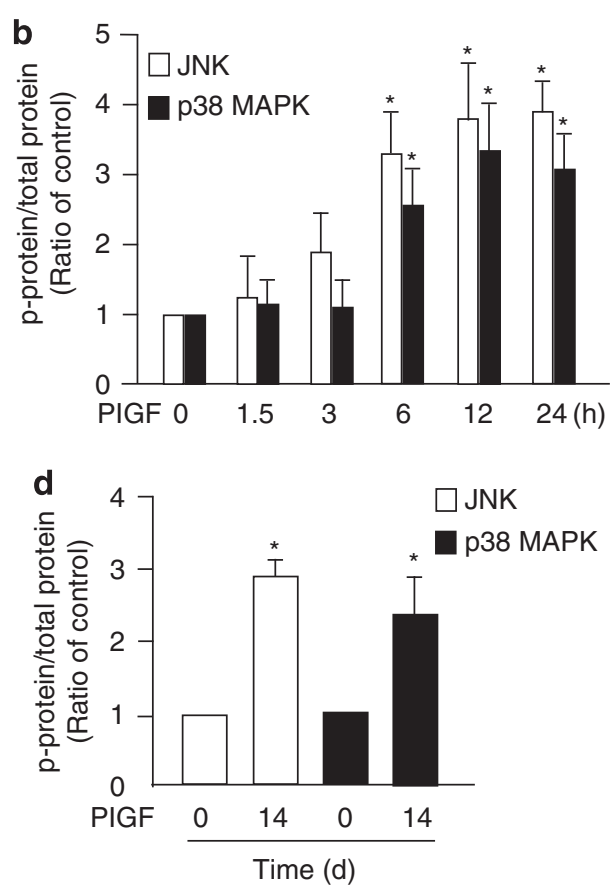

Figure 3 Exogenous PIGF activated c-Jun N-terminal kinase (JNK) and p38 mitogen-activated protein kinase (MAPK) in LE cells. MLE-15 cells were treated with $100 \mathrm{ng} /$ $\mathrm{ml}$ recombinant mouse PIGF for $0-24 \mathrm{~h}(\mathbf{a}$ and $\mathbf{b})$. S cells were treated with $800 \mathrm{pg} / \mathrm{ml}$ recombinant human PIGF for 14 days (c and $\mathbf{d})$. Cellular lysates were subjected to western blot analysis with antibodies for phosphorylated JNK (p-JNK), phosphorylated p38 MAPK (p-p38 MAPK), JNK and p38 MAPK (a and c). The quantitative data are indicated in (b) and (d). Data are presented as mean \pm S.E.M. ${ }^{*} P<0.05$ versus vehicle-treated group

secretion of $\sim 600 \mathrm{pg} / \mathrm{ml}$ PIGF in culture medium from LE cells and instillation of PPE induced secretion of $\sim 100 \mathrm{pg} / \mathrm{ml}$ PIGF in BAL from mice. The difference in the level of PIGF secretion may result from difference in treatment interval and environmental complexity. Our data showed that PPE-induced PIGF expression and secretion, and PIGF-mediated apoptosis occurred, at least in part, in LE cells. The results of this study offer an explanation that COPD patients contain higher levels of PIGF in serum and BAL than non-COPD ones. Furthermore, the knock down of PIGF by siRNA attenuated PPE-induced emphysema and pulmonary apoptosis directly proved that upregulated PIGF has vital role in pathogenesis of emphysema and COPD.

The pathogenesis of COPD is chronic airway inflammation due to neutrophil and macrophage recruitment ${ }^{26,27}$ followed by the secretion of NE and matrix metalloprotease. A protease-antiprotease imbalance may modify gene expression profiles in LE cells to overcome the extracellular stimuli. Previous studies have indicated that NE increases the expressions of elafin, MUC4 and MUC5AC, and the secretion of elafin and mucin in LE cells. ${ }^{16-19}$ In bronchial epithelial cells, NE has also been shown to upregulate the expression of IL-8 through Toll-like receptor-4 signaling. ${ }^{20}$ Using mouse LE cells, PPE was shown to induce the expression of PIGF mRNA and protein in a dose-dependent manner in the present study. According to previous studies, the expression of PIGF in lung tissue was upregulated by hypoxic stimuli and lung stretch $^{23,28}$ and $1.5-\mathrm{kb}$ upstream promoter region was sufficient for hypoxia induction. ${ }^{23}$ We also validated that PPE-induced PIGF mRNA expression was mediated by the interaction of Egr-1 protein and Egr-1 response element in PIGF promoter.

COPD is a major cause of death worldwide. ${ }^{29}$ The levels of airway inflammation and obstruction may insidiously progress, and the early diagnosis and treatment is usually difficult due to the lack of pathognomonic clinical symptoms. Effective biomarker for early detection and therapeutic agents for COPD remain elusive. ${ }^{30,31}$ Cigarette smoke, the major factor related to COPD, has been proven to increase PIGF expression. ${ }^{11}$ In this study, we demonstrated that PPEinduced protease-antiprotease imbalance, the pathogenic mechanism for COPD, increased the expression of PIGF. In future studies, we will explore the mechanisms, such as DNA methylation, small nucleotide polymorphism and microRNA, associated with the regulation of PIGF expression. We hypothesize that PIGF is a prognostic or predictive biomarker for COPD.

Kinase inhibitors for JNK and p38 MAPK have been used as experimental therapeutic strategies in patients with COPD. ${ }^{32,33}$ In the pathogenic processes of COPD, p38 MAPK signaling has been found to have roles in the activation of inflammation cascade and infiltration of immunocytes in vivo and in vitro. ${ }^{34}$ One clinical trial demonstrated a better clinical efficacy in COPD patients receiving p38 MAPK inhibitor therapy. ${ }^{35}$ Our results also demonstrated additional beneficial effects of using JNK and p38 MAPK inhibitors in COPD therapy. First, ablation of JNK and p38 MAPK signaling prevented the PIGF-induced LE cells apoptosis, which is a potential mechanism for COPD. Second, inhibition of JNK and p38 MAPK activity attenuated 
a

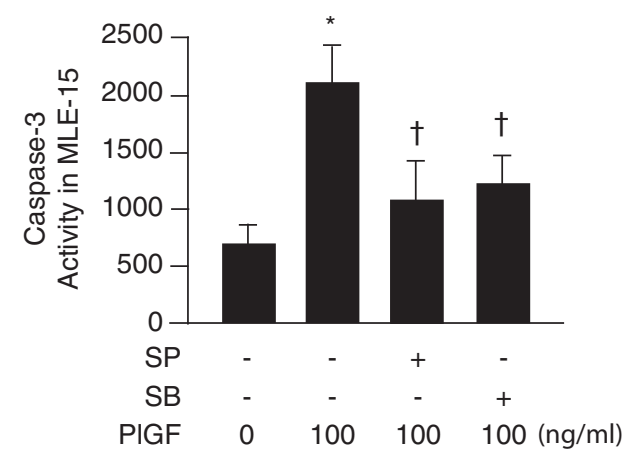

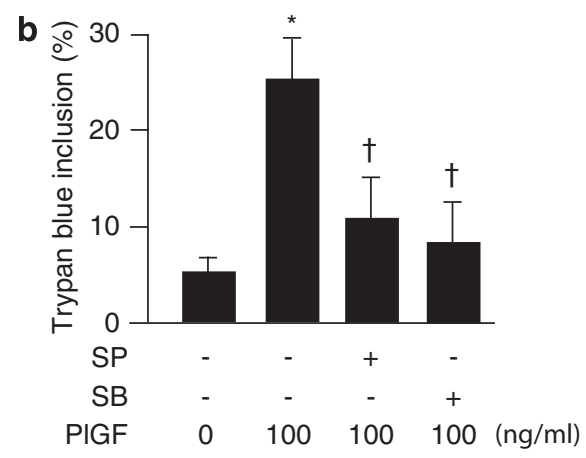

C
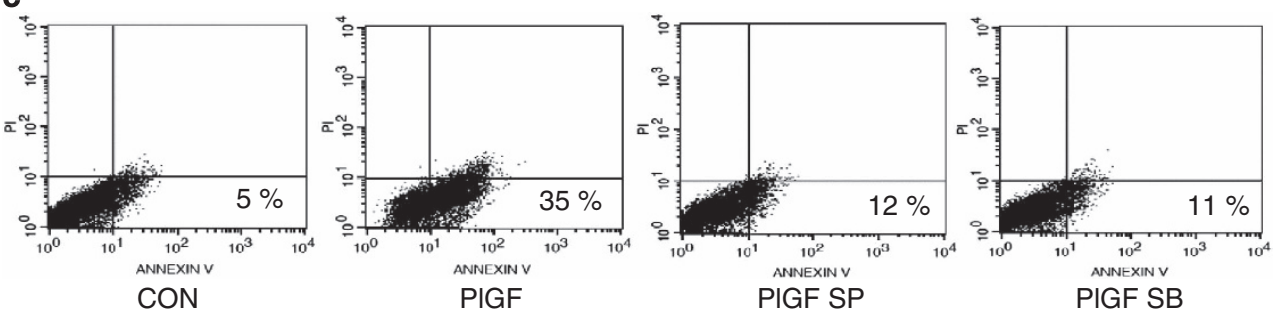

d

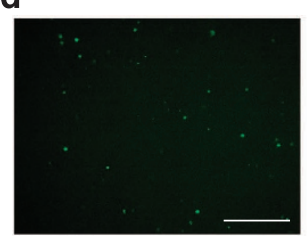

CON

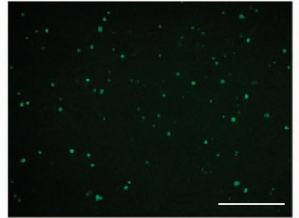

PIGF

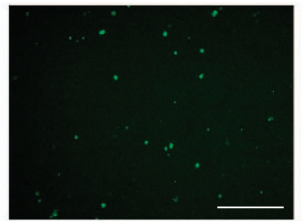

PIGF SP

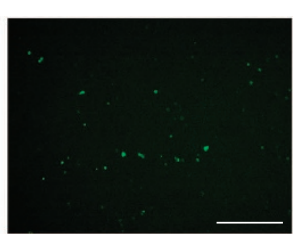

PIGF SB
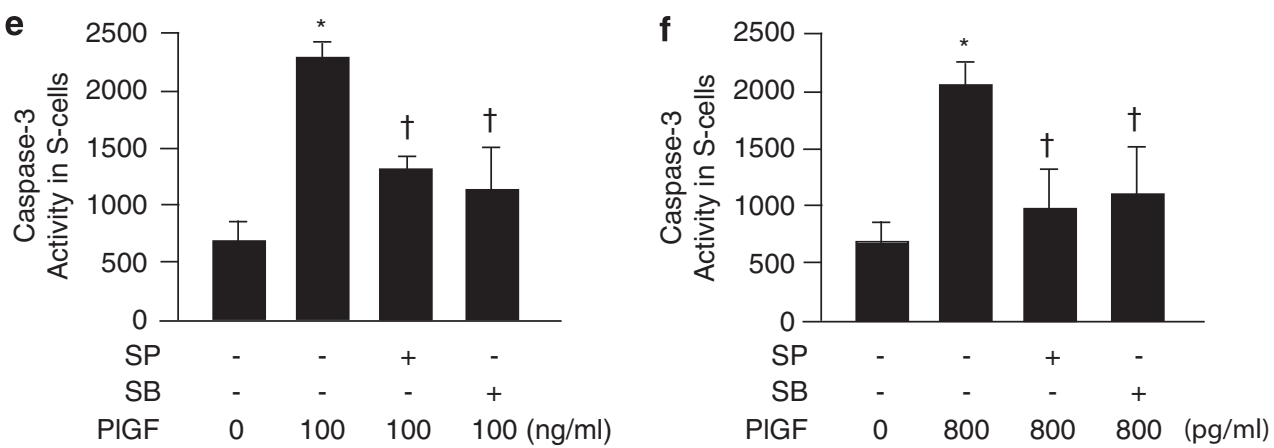

Figure 4 Inhibition of the JNK and p38 MAPK pathways abrogated PIGF-induced apoptosis in LE cells. MLE-15 (a-d) or S cells (e) were pretreated with SP 600125 and SB 203580 (JNK and p38 MAPK inhibitors) for $2 \mathrm{~h}$, and treated with or without $100 \mathrm{ng} / \mathrm{ml}$ recombinant mouse (a-d) or human (e) PIGF for $24 \mathrm{~h}$. S cells were treated with $800 \mathrm{pg} / \mathrm{ml}$ human PIGF, SB 203580 and SP 600125 daily for 14 days (f). The PIGF-induced apoptosis was evaluated by relative signals in a caspase-3 activity assay that are presented as RFU/min per mg protein (a, e and f), blue-stained cells in trypan blue inclusion assay (b), annexin V-FITC-stained cells in flow cytometric assay (c) and fluorescent cells in TUNEL assay (d). Scale bar $=100 \mu \mathrm{m}$. Data are presented as mean \pm S.E.M. ${ }^{*} P<0.05$ versus vehicle-treated group, ${ }^{\dagger} P<0.05$ versus PIGF-treated group

PPE-induced emphysema, which is the major component of COPD.

In conclusion, PPE increased PIGF expression and secretion both in LE cells and lung parenchyma of mice. The contribution of PIGF toward LE cell apoptosis and emphysema development were through JNK and p38 MAPK pathways. Downregulation of PIGF expression and agents inhibiting PIGF-associated downstream signals may be potential therapeutic targets for emphysema and COPD.

\section{Materials and Methods}

Reagents. Rabbit antibodies for phospho-JNK (p-JNK), p-p38 MAPK and p38 MAPK were obtained from Cell Signaling Technology (Beverly, MA, USA). The antibodies for PIGF, JNK and Egr-1, mouse PIGF siRNA, corresponding scramble siRNA and p38 MAPK inhibitor (SB 203580) were purchased from Santa Cruz (Santa Cruz, CA, USA). Trizol reagent, SuperScript III Reverse Transcriptase and Lipofectamine 2000 were obtained from Invitrogen (Carlsbad, CA, USA). Mouse antibody for $\beta$-actin was purchased from Genetex (Irvine, CA, USA). Human and mouse recombinant PIGF protein and an enzyme-linked immunosorbent assay (ELISA) kit were obtained from R\&D Systems (Minneapolis, MN, USA). 
a
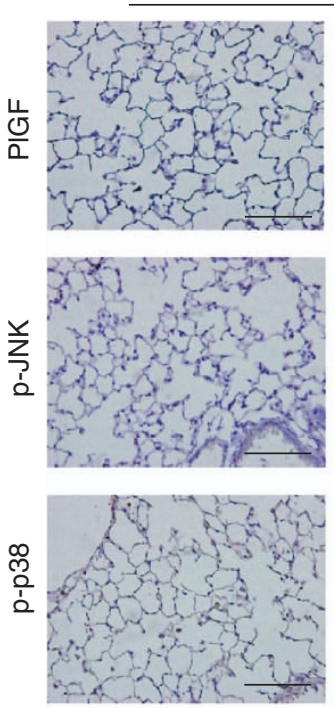

$\mathrm{CON}$
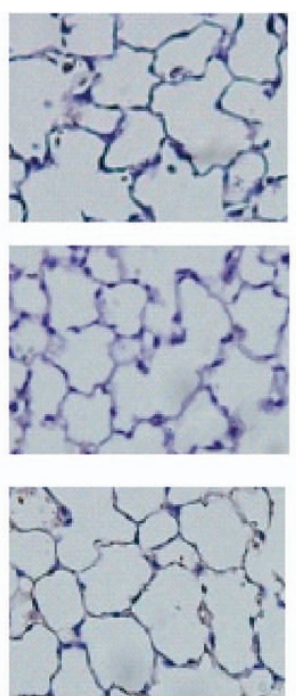

PPE
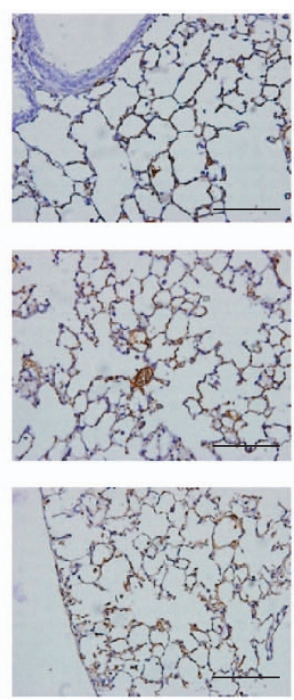
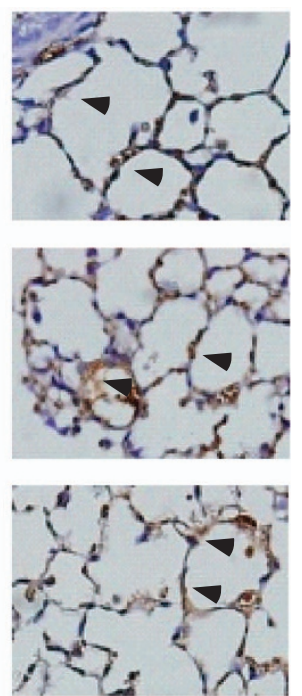

b

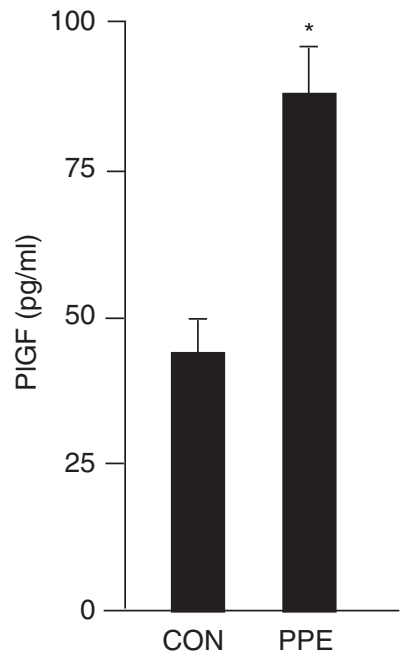

Figure 5 Intratracheal PPE instillation increased PIGF expression and secretion, and downstream JNK and p38 MAPK pathway activation. C57BL/6 mice were intratracheally instilled with saline (CON) and $100 \mathrm{mU} / \mathrm{ml} \mathrm{PPE} \mathrm{(PPE)} \mathrm{weekly} \mathrm{for} \mathrm{one} \mathrm{month.} \mathrm{Paraffin-embedded} \mathrm{lung} \mathrm{tissue} \mathrm{sections} \mathrm{were} \mathrm{used} \mathrm{for} \mathrm{IHC} \mathrm{analysis} \mathrm{and} \mathrm{incubated}$ with antibodies of PIGF, p-JNK and p-p38 MAPK (a). Arrowheads indicated positive stain of PIGF, p-JNK and pP38 MAPK in LE cells. The mice BAL fluid was analyzed for the PIGF level by ELISA (b). Scale bar $=100 \mu \mathrm{m}$. Data are presented as mean \pm S.E.M. ${ }^{\star} P<0.05$ versus vehicle-treated group
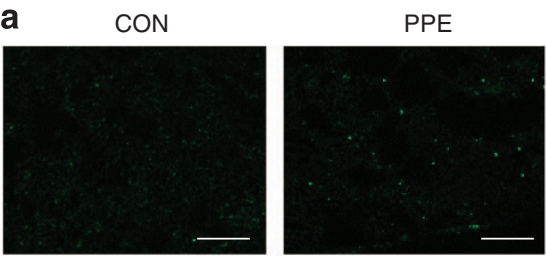

b

CON
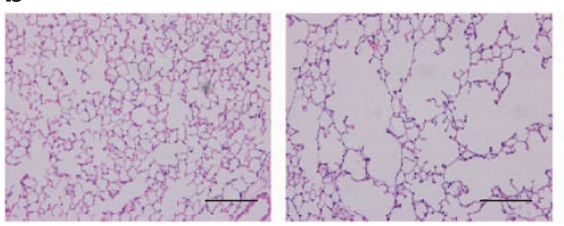

PPE SP

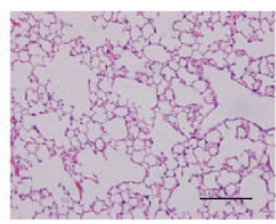

PPE SB

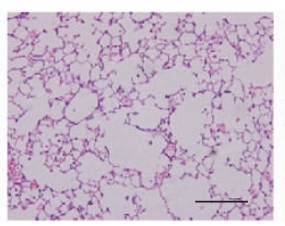

PPE Sc-si

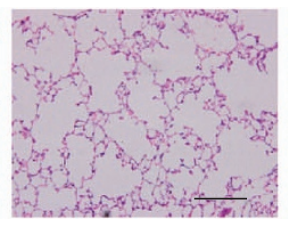

PPE PI-si
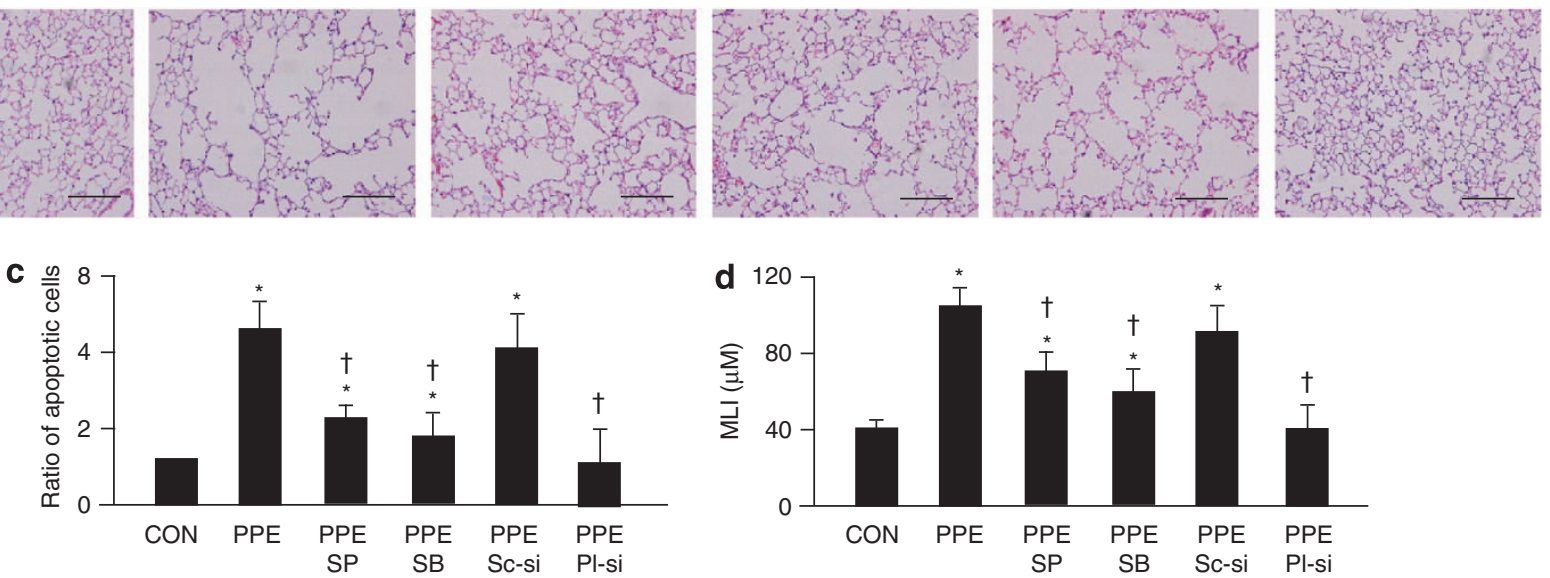

Figure 6 Increased-PIGF and activation of the JNK and p38 MAPK pathways were involved in PPE-induced emphysema in mice. C57BL/6 mice were intratracheally instilled with saline (CON), $100 \mathrm{mU} / \mathrm{ml}$ PPE (PPE), $100 \mathrm{mU} / \mathrm{ml} \mathrm{PPE}$ with $50 \mathrm{mg} / \mathrm{kg} \mathrm{SP} 600125$ (PPE SP), $50 \mathrm{mg} / \mathrm{kg}$ SB 203580 (PPE SB), 3 mg/kg scramble siRNA (PPE Sc-si) and $3 \mathrm{mg} / \mathrm{kg}$ PIGF siRNA (PPE PI-si) weekly for one month. The frozen lung tissue sections were used for TUNEL assay (a) and paraffin-embedded lung tissue sections were used for H\&E stain (b). Apoptotic cells in TUNEL assay were quantified (c) and the mean linear intercepts (MLI) from five independent sections were evaluated (d). Scale bar $=200 \mu \mathrm{m}$. Data are presented as mean \pm S.E.M. ${ }^{*} P<0.05$ versus vehicle-treated group, ${ }^{\dagger} P<0.05$ versus PPE-treated group

A dual-luciferase reporter assay system was obtained from Promega (Madison, WI, USA). Hematoxylin, eosin, caspase-3 activity assay kit, Chromatin immunoprecipitation (ChIP) Assay Kit and EZ-Zyme Chromatin Prep Kit were purchased from Merck-Millipore (Boston, MA, USA). An In Situ Cell Death
Detection Kit was purchased from Roche (Mannheim, Germany). FITC annexin V apoptosis detection kit I was obtained from BD Biosciences (San Jose, CA, USA). The JNK inhibitor, SP600125, was obtained from Enzo Life Science (Plymouth Meeting, PA, USA). A SuperSensitive Polymer-HRP IHC Detection System was 
purchased from Biogenex (Fremont, CA, USA). PPE was obtained from Worthington Biochemical Corporation (Lakewood, NJ, USA).

Animals. This study conformed to the Guide for the Care and Use of Laboratory Animals published by the US National Institutes of Health $(\mathrm{NIH}$ Publication No. 85-23, revised 1996), and all animal experiments were approved by the Institutional Animal Care and Use Committee (IACUC) of the Laboratory Animal Center, College of Medicine and Public Health, National Taiwan University. Eight-week-old male C57BL/6 WT mice were purchased from the Laboratory Animal Center, College of Medicine and College of Public Health, National Taiwan University.

Cell culture. MLE-15 cells were kindly provided by Dr. Tsao. (National Taiwan University, Taiwan). The MLE-15 cells were cultured in DMEM supplemented with $10 \% \mathrm{FBS}, 100 \mathrm{unit} / \mathrm{ml}$ penicillin and $100 \mu \mathrm{g} / \mathrm{ml}$ streptomycin in a humidified $95 \%$ air-5\% $\mathrm{CO}_{2}$ incubator at $37^{\circ} \mathrm{C}$. Human bronchial epithelial cells, S cells (ATCC number CRL-9609), were cultured in F12 nutrient mixture (Carlsbad, CA, USA) with $0.5 \mathrm{ng} / \mathrm{ml}$ recombinant epidermal growth factor, $500 \mathrm{ng} / \mathrm{ml}$ hydrocortisone, $0.005 \mathrm{mg} / \mathrm{ml}$ insulin, $0.035 \mathrm{mg} / \mathrm{ml}$ bovine pituitary extract, $500 \mathrm{nM}$ ethanolamine, $500 \mathrm{nM}$ phosphoethanolamine, $0.01 \mathrm{mg} / \mathrm{ml}$ transferrin, $6.5 \mathrm{ng} / \mathrm{ml} 3,3^{\prime}, 5$-triiodothyronine, $500 \mathrm{ng} / \mathrm{ml}$ epinephrine, $0.1 \mathrm{ng} / \mathrm{ml}$ retinoic acid, $10 \%$ FCS $100 \mathrm{unit} / \mathrm{ml}$ penicillin and $100 \mu \mathrm{g} / \mathrm{ml}$ streptomycin in a humidified $95 \%$ air-5\% $\mathrm{CO}_{2}$ incubator at $37^{\circ} \mathrm{C}$.

Plasmids. Mouse genomic DNA was extracted from the MLE- 15 cells by a Quick-gDNA MiniPrep kit (Zymo Research, Irvine, CA, USA). The 2.5-kb mouse PIGF promoter region was amplified from mouse genomic DNA by PCR that was performed with Hi Fi Taq DNA polymerase (Geneaid, Taipei, Taiwan) as follows: $2 \mathrm{~min}$ at $94^{\circ} \mathrm{C}$, then $15 \mathrm{~s}$ at $94^{\circ} \mathrm{C}, 30 \mathrm{~s}$ at $59^{\circ} \mathrm{C}$, and $2 \mathrm{~min}$ and $30 \mathrm{~s}$ at $72^{\circ} \mathrm{C}$ for 35 cycles. The primers for 2.5 -kb mouse PIGF promoter region were $5^{\prime}$-ATG GTA CCC TCA AGA TAG TCA GGA TAC C-3' (forward primer; underlined, Kpnl site) and $5^{\prime}$-ATA AGC TTT GCA GTC TGC CTG AGC ATC C-3' (reverse primer; underlined, Hindll site). The amplified DNA fragments were cloned into pGL3 vectors (Promega). The sequences were confirmed by DNA sequence analysis.

ELISA. Cellular medium from treated or untreated MLE-15 and BAL fluid from the mice were analyzed by a PIGF ELISA kit (R\&D Systems) according to the manufacturer's instructions.

Luciferase reporter assay. MLE-15 cells were co-transfected with the pGL3-PIGF promoter and pRenilla for $24 \mathrm{~h}$. Treated or untreated MLE-15 cells were collected and analyzed on a dual-luciferase reporter assay system (Promega) by a lumicounter Packard BL10000 according to the manufacturer's instructions.

RT-PCR assay. The total RNA of treated or untreated MLE-15 cells was extracted by Trizol reagent (Invitrogen) according to the manufacturer's instructions. Total RNA ( $5 \mu \mathrm{g}$ ) was used in the RT reactions using a SuperScript III reverse transcriptase kit (Invitrogen) according to the manufacturer's instructions to synthesize the corresponding CDNA. The $250 \mathrm{bp}$ or $530 \mathrm{bp}$ of PIGF or glyceraldehyde 3-phosphate dehydrogenase (GAPDH) cDNA fragments were amplified from the cDNA by PCR, performed with Dream Taq DNA polymerase (Thermo Fisher Scientific Inc., Waltham, MA, USA) as follows: 5 min at $95^{\circ} \mathrm{C}$, then $30 \mathrm{~s}$ at $98^{\circ} \mathrm{C}, 30 \mathrm{~s}$ at $59^{\circ} \mathrm{C}$ and $1 \mathrm{~min}$ at $72{ }^{\circ} \mathrm{C}$ for 35 cycles. The primers for the 250-bp PIGF cDNA fragment were $5^{\prime}$-CAG CCA ACA TCA CTA TGC AG-3' and $5^{\prime}$-GGG TGA CGG TAA TAA ATA CG-3'. The primers for the 530-bp GAPDH CDNA fragment were $5^{\prime}$-GGG CGC CTG GTC ACC AGG GCT G-3' and $5^{\prime}$-GGG GCC ATC CAC AGT CTT CTG-3'.

Protein extraction and immunoblot analysis. Treated or untreated MLE-15 and S cells were lysed using RIPA lysis buffer (Genestar, Taipei, Taiwan), which contained $1 \%$ NP-40, $0.1 \%$ SDS, $150 \mathrm{mM}$ sodium chloride, $0.5 \%$ sodium deoxycholate and $50 \mathrm{mM}$ Tris with a protease inhibitor cocktail (Bionovas, Toronto, Canada) and PhosSTOP (Roche, Basilea, Switzerland). Cellular lysates were centrifuged at 12000 r.p.m. for $5 \mathrm{~min}$ and the resulting supernatant was collected. The extracted protein was quantified by protein assay. Equal amounts of protein were separated using 10\% SDS-polyacrylamide gel electrophoresis and transferred to Immobilon-P membranes (Millipore, MA, USA). After blocking with $5 \%$ skimmed milk, the membranes were incubated with various primary antibodies and then incubated with the corresponding secondary antibodies. The protein bands were detected using an Immobilon Western Chemiluminescent HRP Substrate (Millipore, Billerica, MA, USA) and quantified by ImageQuant 5.2 software (Healthcare Bio-Sciences, Philadelphia, PA, USA).

Chromatin immunoprecipitation (ChIP). Genomic DNA fragment from treated- or untreated-MLE-15 cells were prepared by the EZ-Zyme Chromatin Prep Kit (Millipore) and analyzed by the Chromatin immunoprecipitation (ChIP) Assay Kit (Millipore) to evaluate the associated level of Egr-1 and PIGF promoter region. The antibody of Egr-1 was used for immunoprecipitation and the primer set (5'-CAG AGG TCA CTT AAG TAC CCA GCC ATC T- $3^{\prime}$ and $5^{\prime}$-ATA AGC TTT GCA GTC TGC CTG AGC ATC C-3') were used for amplify of mouse PIGF promoter according to the manufacturer's instructions.

TUNEL assay. Treated or untreated MLE-15 cells and OCT-embedded lung tissue from the mice were analyzed for the level of apoptosis using an In Situ Cell Death Detection Kit (Roche) according to the manufacturer's instructions, and the fluorescence-positive cells were photographed by a Leica DM 4000B microscope (Leica, Solms, Germany).

Trypan blue inclusion assay. Treated or untreated MLE-15 cells were treated with $0-100 \mathrm{ng} / \mathrm{ml}$ PIGF for $24 \mathrm{~h}$ then stained with trypan blue $(1: 1$ in volume), and the cells that stained blue were counted using a hemacytometer counting chamber (Invitrogen).

Caspase-3 activity assay. Treated or untreated MLE-15 and S cells were analyzed for caspase-3 activity using an assay kit (Merck-Millipore) according to the manufacturer's instructions with fluorescent ELISA reader (Molecular Devices, Sunnyvale, CA, USA).

Flow cytometric analysis. Treated or untreated MLE-15 cells were analyzed on an FITC Annexin V Apoptosis Detection Kit I (Becton Drive, Franklin Lakes, NJ, USA) according to the manufacturer's instructions, and the FITCpositive cells were analyzed by a FACS Calibur flow cytometer (Becton Drive).

Immunohistochemistry assay. Paraffin was removed from paraffinembedded tissue sections from the mice by xylene, dehydrated by ethanol and rehydrated by PBS. After treatment of $3 \% \mathrm{H}_{2} \mathrm{O}_{2}$, the sections were applied to a SuperSensitive Polymer-HRP IHC Detection System (Biogenex) and incubated with PIGF, p-JNK and p-p38 MAPK antibodies as the primary antibodies. The stained sections were analyzed by a Leica DM 4000B microscope (Leica).

H\&E stain. Paraffin was removed from paraffin-embedded tissue sections from the mice by xylene, dehydrated by ethanol and rehydrated by PBS. The sections stained with hematoxylin and eosin were then analyzed by a Leica DM 4000B microscope (Leica).

PPE-induced emphysema. The intratracheal instillation of PPE into the C57BL/6 WT mice was performed as described previously. ${ }^{11}$ In brief, eight-weekold mice were instilled intratracheally with saline (CON), $100 \mathrm{mU} / \mathrm{ml}$ PPE (PPE), $100 \mathrm{mU} / \mathrm{ml}$ PPE with $50 \mathrm{mg} / \mathrm{kg}$ JNK inhibitor SP600125 (PPE SP), $50 \mathrm{mg} / \mathrm{kg} \mathrm{p38}$ MAPK inhibitor SB 203580 (PPE SB), 3 mg/kg scramble siRNA (PPE Sc-si) and $3 \mathrm{mg} / \mathrm{kg}$ mouse PIGF siRNA (PPE Pl-si) weekly for one month. The dose of siRNA instillation was according to previous study. ${ }^{36}$ There were five mice in each group. Lung tissue and BAL fluid collection were performed as described previously. ${ }^{10}$

Statistical analysis. The results are presented as mean \pm S.E.M. from five independent repeats and animals. The Mann-Whitney test was used to compare two independent groups. Kruskal-Wallis followed by Bonferroni post-hoc analysis was used for multiple testing. Statistical analyses were performed using SPSS version 8.0 (SPSS Inc., Chicago, IL, USA). A $P$-value $<0.05$ was considered statistically significant.

\section{Conflict of Interest}

The authors declare no conflict of interest. 
Acknowledgements. This study was supported by grants NHRI-EX10110150SI from the National Health Research Institute, Taiwan and FEMH-2013-C-109 from the Far Eastern Memorial Hospital, Taiwan.

1. Decramer M, Janssens W, Miravitlles M. Chronic obstructive pulmonary disease. Lancet 2012; 379: 1341-1351.

2. Fischer BM, Pavlisko E, Voynow JA. Pathogenic triad in COPD: oxidative stress, protease-antiprotease imbalance, and inflammation. Int $J$ Chron Obstruct Pulmon Dis 2011; 6: 413-421.

3. Abboud RT, Vimalanathan S. Pathogenesis of COPD. Part I. The role of protease antiprotease imbalance in emphysema. Int J Tuberc Lung Dis 2008; 12: 361-367.

4. Agusti A, Sobradillo P, Celli B. Addressing the complexity of chronic obstructive pulmonary disease: from phenotypes and biomarkers to scale-free networks, systems biology, and P4 medicine. Am J Respir Crit Care Med 2011; 183: 1129-1137.

5. Sharafkhaneh A, Hanania NA, Kim V. Pathogenesis of emphysema: from the bench to the bedside. Proc Am Thorac Soc 2008; 5: 475-477.

6. Tsao PN, Su YN, Li H, Huang PH, Chien CT, Lai YL et al. Overexpression of placenta growth factor contributes to the pathogenesis of pulmonary emphysema. Am J Respir Crit Care Med 2004; 169: 505-511.

7. De Falco S. The discovery of placenta growth factor and its biological activity. Exp Mol Med 2012; 44: 1-9.

8. Dewerchin M, Carmeliet P. PIGF: a multitasking cytokine with disease-restricted activity. Cold Spring Harb Perspect Med 2012; 2: pii: a011056 doi:10.1101/cshperspect.a011056

9. DiPalma T, Tucci M, Russo G, Maglione D, Lago CT, Romano A et al. The placenta growth factor gene of the mouse. Mamm Genome 1996; 7: 6-12.

10. Cheng SL, Wang HC, Yu CJ, Yang PC. Increased expression of placenta growth factor in COPD. Thorax 2008; 63: 500-506.

11. Li PC, Tsai WH, Chien CT. Dietary monascus adlay supplements facilitate suppression of cigarette smoke-induced pulmonary endoplasmic reticulum stress, autophagy, apoptosis and emphysema-related PLGF in the rat. Food Chem 2013; 136: 765-774.

12. Cheng SL, Wang HC, Yu CJ, Tsao PN, Carmeliet P, Cheng SJ et al. Prevention of elastase-induced emphysema in placenta growth factor knock-out mice. Respir Res 2009 10: 115

13. Shapiro SD. Animal models for COPD. Chest 2000; 117: 223S-227S.

14. Suzuki T, Moraes TJ, Vachon E, Ginzberg HH, Huang TT, Matthay MA et al. Proteinaseactivated receptor-1 mediates elastase-induced apoptosis of human lung epithelial cells. Am J Respir Cell Mol Biol 2005; 33: 231-247.

15. Ginzberg HH, Shannon PT, Suzuki T, Hong O, Vachon E, Moraes T et al. Leukocyte elastase induces epithelial apoptosis: role of mitochondial permeability changes and Akt. Am J Physiol Gastrointest Liver Physiol 2004; 287: G286-G298.

16. Reid PT, Marsden ME, Cunningham GA, Haslett C, Sallenave JM. Human neutrophil elastase regulates the expression and secretion of elafinn (elastase-specific inhibitor) in type II alveolar epithelial cells. FEBS Lett 1999; 457: 33-37.

17. Fischer BM, Cuellar JG, Diehl ML, deFreytas AM, Zhang J, Carraway KL et al. Neutroph elastase increases MUC4 expression in normal human bronchial epithelial cells Am J Physiol Lung Cell Mol Physiol 2003; 284: L671-L679.

18. Shao MX, Nadel JA. Neutrophil elastase induces MUC5AC mucin production in human airway epithelial cells via a cascade involving protein kinase $C$, reactive oxygen species, and TNF- $\alpha$-converting enzyme. J Immunol 2005; 175: 4009-4016.

19. Park JA, He F, Martin LD, Li Y, Chorley BN, Adler KB. Human neutrophil elastase induces hypersecretion of mucin from well-differentiated human bronchial epithelial cells in vitro via a protein kinase C-mediated mechanism. Am J Pathol 2005; 167: 651-661.
20. Devaney JM, Greene CM, Taggart CC, Carroll TP, O'Neill SJ, McElvaney NG Neutrophil elastase up-regulates interleukin-8 via toll-like receptor 4. FEBS Lett 2003; 544: 129-132.

21. Geraghty P, Rogan MP, Greene CM, Boxio RM, Poiriert T, O'Mahony M et al. Neutrophil elastase up-regulates cathepsin $\mathrm{B}$ and matrix metalloprotease-2 expression. J Immuno 2007; 178: 5871-5878.

22. Mura M, dos Santos CC, Stewart D, Liu M. Vascular endothelial growth factor and related molecules in acute lung injury. J Appl Physiol 2004; 97: 1605-1617.

23. Green CJ, Lichtlen P, Huynh NT, Yanovsky M, Laderoute KR, Schaffner W et al. Placenta growth factor gene expression is induced by hypoxia in fibroblasts: a central role for metal transcription factor-1. Cancer Res 2001; 61: 2696-2703.

24. Krämer B, Meichle A, Hensel G, Charnay P, Krönke M. Characterization of an Krox-24/Egr-1responsive element in the human tumor necrosis factor promoter. Biochim Biophys Acta 1994; 1219: 413-421

25. Nakajoh M, Fukushima T, Suzuki T, Yamaya M, Nakayama K, Sekizawa K et al. Retinoic acid inhibits elastase-induced injury in human lung epithelial cell lines. Am J Respir Cell Mol Biol 2003; 28: 296-304

26. Roghanian A, Sallenave JM. Neutrophil elastase (NE) and NE inhibitors: canonical and noncanonical functions in lung chronic inflammatory diseases (cystic fibrosis and chronic obstructive pulmonary disease). J Aerosol Med Pulm Drug Deliv 2008; 21: 125-144

27. Lagente V, Le Quement C, Boichot E. Macrophage metalloelastase (MMP-12) as a target for inflammatory respiratory diseases. Expert Opin Ther Targets 2009; 13: 287-295.

28. Mohammed KA, Nasreen N, Tepper RS, Antony VB. Cyclic stretch induces PIGF expression in bronchial airway epithelial cells via nitric oxide release. Am J Physiol Lung Cell Mol Physiol 2007; 292: L559-L566.

29. Mathers CD, Loncar D. Projections of global mortality and burden of disease from 2002 to 2030 p38 MAP kinase inhibitors: a future therapy for inflammatory diseases. PLoS Med 2006; 3: e442.

30. Agustí A, Barnes PJ. Update in chronic obstructive pulmonary disease 2011. Am J Respir Crit Care Med 2012; 185: 1171-1176.

31. Rosenberg SR, Kalhan R. Biomarkers in chronic obstructive pulmonary disease. Trans/ Res 2012; 159: 228-237.

32. Adcock IM, Caramori G. Kinase targets and inhibitors for the treatment of airway inflammatory diseases. Bio Drugs 2004; 18: 167-180.

33. Banerjee A, Koziol-White C, Panettieri R Jr. p38 MAPK inhibitors, IKK2 inhibitors, and TNFa inhibitors in COPD. Curr Opin Pharmacol 2012; 12: 287-292.

34. Renda T, Baraldo S, Pelaia G, Bazzan E, Turato G, Papi A et al. Increased activation of p38 MAPK in COPD. Eur Respir J 2008; 31: 62-69.

35. Mayer RJ, Callahan JF. p38 MAP kinase inhibitors: a future therapy for inflammatory diseases. Drug Discov Today Ther Strateg 2006; 3: 49-54.

36. Lomas-Neira JL, Chung CS, Wesche DE, Perl M, Ayala A. In vivo gene silencing (with siRNA) of pulmonary expression of MIP-2 versus KC results in divergent effects on hemorrhage-induced, neutrophil-mediated septic acute lung injury. J Leukoc Biol 2005; 77 : 846-853.

(c) (1) (2) Cell Death and Disease is an open-access journal
published by Nature Publishing Group. This work is
licensed under a Creative Commons Attribution-NonCommercial-
ShareAlike 3.0 Unported License. To view a copy of this license, visit
http://creativecommons.org/licenses/by-nc-sa/3.0/

\section{Supplementary Information accompanies this paper on Cell Death and Disease website (http://www.nature.com/cddis)}

